\title{
The Correlation between Rheumatological Manifestations and Diabetes Complications and Indices
}

\author{
Amandeep Singh ${ }^{1}$, Sanaulla Khan Pathan ${ }^{2}$, Husan Pal ${ }^{3}$ \\ ${ }^{1}$ Medical Officer, CHC Bhadson, Patiala, Punjab, India, ²Junior Resident, Rajindra Hospital, Patiala, Punjab, India, ${ }^{3}$ Medical Officer, CHC Guruharasahai, Ferozepur, \\ Punjab, India.
}

\section{Abstract}

Background: Type 2 diabetes mellitus represents approximately $90 \%$ of all cases of diabetes. Nonvascular complications include gastrointestinal, genitourinary, dermatologic, infectious periodontal disease and rheumatological. Diabetic amyotrophy is characterized by muscle weakness and wasting, and by diffuse, proximal lower limb muscle pain, and asymmetrical loss of tendon jerks. There have been not much studies on diabetes and its association between rheumatological manifestations. Therefore, the present study was conducted with the aim to determine the correlation between rheumatological manifestations and diabetes complications and indices. Subjects and Methods: The present cross sectional study enrolled 100 subjects reporting to Department of Medicine, Rajindra Hospital/ Government Medical College, Patiala. Complete blood count, erythrocyte sedimentation rate, rheumatoid factor, serum uric acid were done. The rheumatoid factor upto $20 \mathrm{IU} / \mathrm{dl}$ and serum uric acid upto $7 \mathrm{mg} / \mathrm{dl}$ was taken as normal. X-rays of hand, shoulder, knee, spine and other involved joints wherever necessary were done. Examination of musculoskeletal system was performed. All the data thus obtained was arranged in a tabulated form and analyzed using SPSS software. Student t test was used for statistical analysis. Probability value of less than 0.05 was considered as significant. Results: Mean value of HbA1C of patients with rheumatological manifestations was $8.43 \pm 1.14$ whereas Mean value of HbA1C of patients without rheumatological manifestations was 7.10 \pm 0.93 . On statistical analysis significant association between rheumatological manifestations and $\mathrm{HbA1c}$ was found. On statistical analysis positive association between rheumatological manifestations and retinopathy was noted. Conclusion: Positive association of retinopathy and neuropathy was seen in our study with rheumatological manifestations in T2DM. So, screening of diabetic patients for the presence of rheumatic complications is needed, since early recognition of these lessens the chances of irreversible damage.

Keywords: Cross Sectional, Diabetes, Rheumatological, Complications.

Corresponding Author: Dr. Sanaulla Khan Pathan, Junior Resident, Rajindra Hospital, Patiala, Punjab, India.

Received: September 2019

Accepted: September 2019

\section{Introduction}

Type 2 diabetes mellitus represents approximately $90 \%$ of all cases of diabetes. It usually occurs in older overweight individuals. It is thought that while the primary defect may be insulin resistance, many of these patients also have poor insulin production, particularly for their level of glycemia. ${ }^{[1]}$ Chronic complications of diabetes mellitus can be divided into vascular and non-vascular complications. Vascular complications comprise of microvascular (retinopathy, neuropathy, nephropathy) and macrovascular (coronary artery disease, peripheral vascular disease, cerebrovascular disease). Nonvascular complications include gastrointestinal, genitourinary, dermatologic, infectious periodontal disease and rheumatological. ${ }^{[2]}$ Diabetic amyotrophy Is characterized by muscle weakness and wasting, and by diffuse, proximal lower limb muscle pain, and asymmetrical loss of tendon jerks. The shoulder girdle may be affected, but less commonly. It typically occurs in older men with type 2 diabetes, and is often associated with weight loss. ${ }^{[3]}$ the condition is most likely caused by inflammatory,

immune-mediated

vascular radiculoplexopathy. ${ }^{[4]}$ A large body of evidence indicates that osteoarthritis is part of a generalized metabolic disorder in which various interrelated metabolic factors contribute to the osteoarthritis process. ${ }^{[5]}$ Gout is a heterogenous disorder characterized by hyperuricemia and arthritis. It usually affects lower extremities. ${ }^{[6]}$ There have been not much studies on diabetes and its association between rheumatological manifestations. Therefore, the present study was conducted with the aim to determine the correlation between rheumatological manifestations and diabetes complications and indices.

\section{Subjects and Methods}

The present cross sectional study enrolled 100 subjects reporting to Department of Medicine, Rajindra Hospital/ Government Medical College, Patiala. The study was approved by the institutional ethical board and all the subjects were informed about the study and a written consent was obtained from them in their vernacular 
language. Subjects with history of diabetes mellitus for at least 2 years were included in the study. Patients with rheumatoid arthritis or Patients with primary joint disease. like, infective arthritis, traumatic arthritis and primary gouty arthritis were not included in the study. A detailed history of each patient was be taken as per proforma attached. Complete clinical examination was done and all the routine investigations as in proforma were undertaken. Fasting and postprandial blood sugars were done. Renal function tests including blood urea, serum creatinine and urine analysis were also done. Urine was analysed for sugars, ketone bodies and protein. Complete blood count, erythrocyte sedimentation rate, rheumatoid factor, serum uric acid were done. The rheumatoid factor upto $20 \mathrm{IU} / \mathrm{dl}$ and serum uric acid upto $7 \mathrm{mg} / \mathrm{dl}$ was taken as normal. X-rays of hand, shoulder, knee, spine and other involved joints wherever necessary were done. Examination of musculoskeletal system was performed. Firstly, the hands were checked, followed by the shoulders, then spine, and finally the lower limbs. All the data thus obtained was arranged in a tabulated form and analyzed using SPSS software. Student $t$ test was used for statistical analysis. Probability value of less than 0.05 was considered as significant.

\section{Results}

[Table 1] illustrates the association of rheumatological manifestations with blood indices amongst diabetic patients. Mean value of $\mathrm{HbA} 1 \mathrm{C}$ of patients with rheumatological manifestations was $8.43 \pm 1.14$ whereas Mean value of $\mathrm{HbA1C}$ of patients without rheumatological manifestations was 7.10 \pm 0.93 . On statistical analysis significant association between rheumatological manifestations and HbA1c was found. The mean value of FBS among patients with rheumatological manifestations was $157.89 \pm 53.40$ $\mathrm{mg} / \mathrm{dl}$. The mean value of FBS among patients without rheumatological manifestations was $156.04 \pm 58.24 \mathrm{mg} / \mathrm{dl}$. No statistically significant association was noted between mean fasting blood sugar levels and the prevalence of rheumatological manifestation in diabetics. The mean value of PPBS among patients with rheumatological manifestations was $238.22 \pm 60.29 \mathrm{mg} / \mathrm{dl}$. The mean value of PPBS among patients without rheumatological manifestations was and $239.84 \pm 60.96 \mathrm{mg} / \mathrm{dl}$. No statistically significant association was noted between mean post-prandial blood sugar levels and the prevalence of rheumatological manifestation in diabetics.

[Table 2] shows the association between rheumatological manifestations and diabetic complications. Out of 27 patients with rheumatological manifestations 10 had retinopathy and 17 had no retinopathy. Out of 73 patients without rheumatological manifestations, 9 had retinopathy and 64 had retinopathy. On statistical analysis positive association between rheumatological manifestations and retinopathy was noted. Out of 27 patients with rheumatological manifestations, 6 had nephropathy and 21 had no nephropathy. Out 73 patients without rheumatological manifestations, 13 had nephropathy and 60 had no nephropathy. In our study, rheumatological manifestations had non-significant association with nephropathy. Out of 27 patients with rheumatological manifestations 16 had neuropathy and 11 had neuropathy. Out of 73 patients without rheumatological manifestations, 25 had neuropathy and 48 had no neuropathy. In present study we had significant associations between rheumatological manifestations and neuropathy.

Table 1: Association of rheumatological manifestations with blood indices

\begin{tabular}{|l|l|l|}
\hline $\begin{array}{l}\text { Rheumatological } \\
\text { Manifestations }\end{array}$ & Hb1Ac (Mean \pm S.D) & P value \\
\hline Yes & $8.43 \pm 1.14$ & $<0.05$ \\
\hline No & $7.10 \pm 0.93$ & \\
\hline & FBS (Mean \pm S.D) & \\
\hline Yes & $157.89 \pm 53.40$ & $>0.05$ \\
\hline No & $156.04 \pm 58.24$ & \\
\hline & PPBS (Mean \pm S.D) & \\
\hline Yes & $238.22 \pm 60.29$ & $>0.05$ \\
\hline No & $239.84 \pm 60.96$ & \\
\hline
\end{tabular}

Table 2: Association of Rheumatological Manifestations with Diabetic Complications

\begin{tabular}{|c|l|l|l|}
\hline Complications & $\begin{array}{l}\text { With } \\
\text { Rheumatological } \\
\text { manifestations }\end{array}$ & $\begin{array}{l}\text { Without } \\
\text { Rheumatological } \\
\text { manifestations }\end{array}$ & P value \\
\hline Retinopathy & & & \\
\hline Yes & 10 & 9 & 0.005 \\
\hline No & 17 & 64 & \\
\hline Nephropathy & & & $>0.05$ \\
\hline Yes & 6 & 13 & \\
\hline No & 21 & 60 & $<0.05$ \\
\hline Neuropathy & & & \\
\hline Yes & 16 & 25 & \\
\hline No & 11 & 48 & \\
\hline
\end{tabular}

\section{Discussion}

Ramchurn et al (2009) did a study of 96 persons with diabetes and looked for rheumatological manifestations and found that locomotor disease was present in $75 \%$ of diabetics with the upper limb the commonest site for abnormalities. The mean $\mathrm{HbA1c}$ was significantly higher in patients with combined shoulder and hand problems $(9.1 \%)$ than in those with no upper limb problems (8.0\%) $[\mathrm{p}=0.018]$. They concluded that Upper limb locomotor abnormalities are very common in diabetes and are associated with worse glycaemic control and more diabetic complications. Assessment of upper limb locomotor disease in diabetes should include an estimate of glycaemic control and a search for other complications. ${ }^{[7]}$ Serban and Udrea (2012) studied musculoskeletal complications in diabetic patients and found that prevalence of diabetic cheiroarthropathy, ranges from $8 \%$ to $50 \%$ among patients with diabetes, compared with only $4 \%$ to $20 \%$ among individuals without DM. The prevalence of Dupuytren's Contracture in diabetes ranges between $20 \%$ and $63 \%$, higher than among subjects without diabetes i.e, 13\%. The estimated prevalence of Neuropathic arthritis (Charcot joints, diabetic osteoarthropathy) is $11-30 \%$ in diabetic patients. ${ }^{[8]}$ Bhat et al (2016) found that in their study 33\% of 
patients had musculoskeletal manifestations. In their study osteoarthritis was present in a significant number of our patients thereby contributing to a pes anserinitis independently. All the upper limb figures showed a statistically significant difference i.e. $\mathrm{P}$ value $<0.05$. $^{[9]}$ In our study association of $\mathrm{HbA1C}$ with prevalence of rheumatological manifestations in T2DM was highly significant. This is in agreement with studies done by Mathew et al, ${ }^{[10]}$ and Agrawal et al. ${ }^{[1]]}$ The mean value of FBS among type 2 diabetics with rheumatological manifestations was $157.89 \pm 53.40 \mathrm{mg} / \mathrm{dl}$. The mean value of FBS among type 2 diabetics without rheumatological manifestations was $156.04 \pm 58.24 \mathrm{mg} / \mathrm{dl}$. No statistically significant association was noted between mean fasting blood sugar levels and the prevalence of rheumatological manifestations in diabetics. This is in consistency with study done by Kumar et al. ${ }^{[12]}$ The mean value of PPBS among type 2 diabetics with rheumatological manifestations was $238.22 \pm 60.29 \mathrm{mg} / \mathrm{dl}$. The mean value of PPBS among type 2 diabetics without rheumatological manifestations was $239.84 \pm 60.96 \mathrm{mg} / \mathrm{dl}$. No statistically significant association was noted between mean post prandial blood sugar levels and the prevalence of rheumatological manifestations in diabetics. This is in consistency with study done by Kumar et al. ${ }^{[12]}$ Pandey et al, ${ }^{[13]}$ in their study found significant association of retinopathy with rheumatological manifestations. Abourazzak et al, ${ }^{[14]}$ showed significant association of vascular complications with rheumatological manifestations, retinopathy was seen $35 \%$ of subjects with articular and abarticular manifestations. This agrees with the present study. Present study showed no associations of rheumatological manifestations with nephropathy. This non significant associations was also found in several other studies like Cagliero et al, ${ }^{[15]}$ and Attar et al. ${ }^{[16]}$ In Present study we found significant association of rheumatological manifestations with neuropathy. Pandey et al, ${ }^{[12]}$ and Attar et $a{ }^{\left[{ }^{[16]}\right.}$ also had similar observations. Abourazzak et al ${ }^{[14]}$ in their study had shown significant association of vascular complications with rheumatological manifestations.

\section{Conclusion}

Positive association of retinopathy and neuropathy was seen in our study with rheumatological manifestations in T2DM. So diabetic patients with retinopathy and neuropathy have more chances of rheumatological manifestations.
Statistically significant association of $\mathrm{HbA1c}$ with rheumatological manifestations was noticed. It indicates that poor glycaemic control increases prevalence of rheumatological manifestations. So, screening of diabetic patients for the presence of rheumatic complications is needed, since early recognition of these lessens the chances of irreversible damage.

\section{References}

1. Tataroglu C, Bicerol B, Kiylioglu N, Ozkul A, Akyol A. Proximal femoral conductions in patients with lumbosacral radiculoplexus neuropathy. Clin Neurol Neurosurg. 2007;109(8):654-60

2. Powers A. Diabetes Mellitus. In : Kasper D, Fauci A, Longo D, Hauser S, Larry Jameson J, Loscalzo J (eds). Harrison's Principles of Internal Medicine (19th edn.). New York: Mcgraw-Hill 2015;2399-425.

3. Smith LL, Burnet SP, McNeil JD. Musculoskeletal manifestations of diabetes mellitus. Br J Sports Med 2003;37(1):30-5.

4. Dyck PJ, Norell JE, Dyck PJ. Microvasculitis and ischemia in diabetic lumbosacral radiculoplexus neuropathy. Neurology 1999;53(9):21132 .

5. Velasquez M, Katz J. Osteoarthritis: Another Component of Metabolic Syndrome? Metab Syndr Relat Disord 2010;8(4):295-305.

6. Fornasier VL, Littlejohn G, Urowitz MB, Keystone EC, Smythe HA. Spinal entheseal new bone formation: the early changes of spinal diffuse idiopathic skeletal hyperostosis. J Rheumatol. 1983;10(6): 939-47.

7. Ramchurn N, Mashamba C, Leitch E, Arutchelvam V, Narayanan K, Weaver $\mathbf{J}$ et al. Upper limb musculoskeletal abnormalities and poor metabolic control in diabetes. Eur J Intern Med 2009;20(7):718-21.

8. Serban AL, Udrea GF. Rheumatic manifestations in diabetic patients. J Med Life 2012;5(3):252-7

9. Bhat T, Dhar S, Dar T. The Musculoskeletal Manifestations of Type 2 Diabetes Mellitus in a Kashmiri Population. Int $\mathrm{J}$ Health Sci 2016;10(1):55-66.

10. Mathew AJ, Nair JB, Pillai SS. Rheumatic-musculoskeletal manifestations in type 2 diabetes mellitus patients in south India. Int J Rheum Dis 2011;14(1):55-60.

11. Agrawal RP, Gothwal S, Tantia P, Agrawal R, Rijhwani P, Sirohi P, et al. Prevalence of rheumatological manifestations in diabetic population from North-West India. J Assoc Physicians India 2014;62:788-92.

12. Kumar CR, Rampure D. Clinical Study of Rheumatological Manifestations in Type 2 Diabetes Mellitus Patients. J Med Sci Clin Res 2015;3(10):8086-101.

13. Pandey A, Usman K, Reddy H, Gutch M, Jain N, Qidwar SA. Prevalence of Hand Disorders in Type 2 Diabetes Mellitus and its Correlation with Microvascular Complications. Ann Med Health Sci Res 2013;3(3):349-54.

14. Abourazzak FE, Akasbi N, Houssaini GS, Bazouti S, Bensbaa S, Hachimi $\mathrm{H}$ et al. Articular and abarticular manifestations in type 2 diabetes mellitus. Eur J Rheumatol 2014;1(4):132-34.

15. Cagliero E, Apruzzese W, Perlmutter GS, Nathan DM. Musculoskeletal disorders of the hand and shoulder in patients with diabetes mellitus. Am J Med 2002;112(6):487-90.

16. Attar SM. Musculoskeletal manifestations in diabetic patients at a tertiary center. Libyan J Med 2012;7(1):19162.

Copyright: (C) the author(s), 2019. It is an open-access article distributed under the terms of the Creative Commons Attribution License (CC BY 4.0), which permits authors to retain ownership of the copyright for their content, and allow anyone to download, reuse, reprint, modify, distribute and/or copy the content as long as the original authors and source are cited.

How to cite this article: Singh A, Pathan SK, Pal H. The Correlation between Rheumatological Manifestations and Diabetes Complications and Indices. Asian J. Med. Res. 2019;8(3):ME13-ME15.

DOI: dx.doi.org/10.21276/ajmr.2019.8.3.ME5

Source of Support: Nil, Conflict of Interest: None declared. 